\title{
Online Mindfulness Experience for Emotional Support to Healthcare staff in times of Covid-19
}

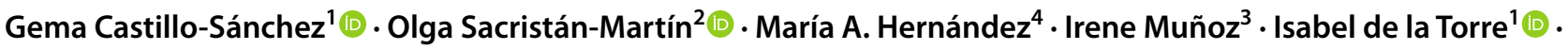 \\ Manuel Franco-Martín ${ }^{3,4}$
}

Received: 27 October 2021 / Accepted: 17 January 2022 / Published online: 26 January 2022

(c) The Author(s) 2022

\begin{abstract}
During the first confinement in Spain, between the months of March to June 2020, Information and Communication Technologies strategies were implemented in order to support health workers in the Wellbeing of Mental Health. Faced with so much uncertainty about the pandemic, an Online Mindfulness course. The objective of the course was to support healthcare professionals in Castilla y León in managing stress, anxiety and other emotional disturbances generated by coping with a situation as uncertain and unexpected as a pandemic, in order to manage emotions and thoughts that can lead to suicidal ideation. The motivations for the demand, reasons or motivations in which the health professionals of Castilla y León decided to participate in the mindfulness course in the first wave of Covid-19 in Spain are described. The descriptive and inferential statistical analysis of the customer satisfaction survey applied at the end of the mindfulness course, to the health professionals who participated in a satisfaction survey (CSQ-8: Client Satisfaction Questionnaire). Professional were asked to complete a survey based on (CSQ-8: Client Satisfaction Questionnaire) whose Cronbach's alpha $=0.917$ is why the instrument used with $\mathrm{N}=130$ participants has high reliability. The $66 \%$ answered with a highly satisfied that they would return to the mindfulness online course. The $93 \%$ of the people who answered the satisfaction survey were women, of which they are professionals in the nursing area, with a participation of around $62 \%$. In relation to the online system used in the Mindfulness intervention, $74 \%$ expressed that they fully agreed that it has been easy to use the online system for the mindfulness intervention. Health Professionals responded with 58\% high satisfaction and 36\% satisfaction, making a total of $94 \%$ on the help received in the online mindfulness courses to solve their problems. There is no difference between the age groups of the professionals who have preferred the Mindfulness online course $(\mathrm{p}=0.672)$.
\end{abstract}

Keywords Mindfulness $\cdot$ Online $\cdot$ COVID-19 $\cdot$ CSQ- $8 \cdot$ Survey $\cdot$ Mental health $\cdot$ Spain

\section{Introduction}

During the epidemic 2020, health workers on the front lines often come to a very high pressure for care, including increased risk of infection and contamination, as well as frustration, work

Gema Castillo-Sánchez

gemaanabel.castillo@alumnos.uva.es; gemacs17@gmail.com

Olga Sacristán-Martín

olgasacristan@gmail.com

María A. Hernández

marewira@gmail.com

Irene Muñoz

imunozle@saludcastillayleon.es

Isabel de la Torre

isator@tel.uva.es overload, isolation, management of patients and families with negative feelings, due to risk of contagion $[1,2]$.

In addition, the fear of infecting their relatives through their work, which in many cases leads them to isolate themselves from the family or loved ones [2]. Even, in 
previous experiences, it has been seen that the risk of post-traumatic stress disorder increases, when the professional's quarantine is associated with the infection of a family member [3].

In the treatment of the epidemic caused by covid-19 [4] The Chinese experience has frequently shown that stress and panic reactions occur in both health workers and affected patients [2, 5].

The importance that goes beyond mental suffering and loss of performance, but will also generate a decrease in the immune protection capacity of their own body that will expose them to a greater risk of infection [6]. Some studies show a high suicide rate in the group of health professionals [7], which is being particularly affected and at risk in the battle against COVID-19. This situation fosters a global debate about the concerns of healthcare professionals about the spread and management of infection, exposure of family members, sick colleagues, and work stress [8]. This group of professionals deserves emotional support services in their work, which is why the initiative arises to offer Mindfulness [9] online.

During the Covid-19 pandemic there are innovative opportunities for the use of technologies to maintain social distancing, monitor mental health [10] and assist the sick [11]. Mobile health services appear to be highly reliable for digital psychological intervention [12].

A high prevalence of psychological distress has been estimated in professionals facing the pandemic [13] and psychological disorders associated with the situation [14], as well as stress affects their behavior [15]. This study presented an immense literature pertinent to the prevalence and diagnosis of stress in humans [16]. It is advisable to support the work of professionals and mental health should be monitored regularly using emerging technologies in times of pandemic [17].

Some interventions, such as Mindfulness-Based Cognitive Therapy (MBCT) [18] have shown that they can protect people from depression [19] and can also facilitate a change in self-regulation goals to prevent suicide [20].

During the first wave of the pandemic, health professionals in Castilla y León (Valladolid and Zamora) used this online therapy as support for the management of stress [21], anxiety [19] and other alterations in emotional and mental health contributing directly to suicide prevention [7, 8, 22].

In this article we aim to assess the degree of satisfaction and results of a first approach to the intervention through mindfulness applied online to promote emotional control of the professionals of the Health staff of Castilla y León. The remainder of this paper is a follows methods, results, discussion and conclusions and how this may apply to other health care employees.

\section{Methods}

In the first confinement in Spain during the months of March to June 2020, strategies were organized involving Information and Communication Technologies [23] to be able to support health workers in the Mental Health Wellness. Faced with so much uncertainty about the pandemic, an Online Mindfulness course [9] was organized using the ZOOM videoconference platform [24] and published on the website www.massaludmental.es [25] for healthcare professionals in Castilla y León. The objective of the course was to support healthcare professionals in Castilla y León in managing stress, anxiety and other emotional disturbances generated by coping with a situation as uncertain and unexpected as an outbreak, in order to manage emotions and thoughts that can lead to suicidal ideation.

This initiative began on April 20 and ended on June 28, 2020. In total, 24 sessions of 40 min duration were held, twice a week, in the morning and afternoon shift online.

The organization of this initiative included as a first stage the online registration to be able to send them by mail the links of the course and the planning of sessions. Through enrollment, questions were asked related to the motive and reasons that prompted them to participate in the mindfulness course. All was offered free for health workers.

The methodology used to assess the impact of mindfulness on health professionals in Castilla y León, consists of the following steps:

- The motivations for the demand, reasons or motivations in which the health professionals of Castilla y León decided to participate in the mindfulness course in the first wave of Covid-19 in Spain are described. The number of registered is equal to $\mathrm{N}=359$ professionals. However, with regard to the question about the reason for the lawsuit, 340 responded. Details on the registration of participants can be found in the appendix in Table 7 .

- The descriptive and inferential statistical analysis of the customer satisfaction survey applied at the end of the mindfulness course, to the health professionals who participated in a satisfaction survey (CSQ-8: Client Satisfaction Questionnaire) [26], in which they could answer in an anonymous and not mandatory. The number of professionals who answered is equal to $\mathrm{N}=130$. Details on the satisfaction survey applied can be found in the appendix in Table 8.

The descriptive and inferential statistics was carried out with samples collected for non-probabilistic convenience [27]. This was due to the ease of access and the availability of the professionals who participated in the mindfulness 
course. The tool used for the analysis was the Statistical Package for Social Sciences 24 (SPSS). The analysis of the open questions of this course have been published in another article [28].

\section{Results}

A total of 359 health professionals participated, mostly belonging to the Zamora and Rio Hortega University hospitals, there were participants from all over Spain, mainly from Castilla y León, reaching a total of 359 participants. The main statistical data obtained on the registration of the course are presented in Tables 2, 3, and 4:

According to Table 1, the professionals at the beginning of the first wave of the pandemic demanded this type of intervention, the main reasons, for which the health professionals required this course were: Anxiety (124), Insomnia (38), Depressive mood (12), psycho-emotional support (140) and others (26). Additionally, work stress was reported by 213 registered participants, followed by stress for relatives (patients with Covid-19) with 10, stress due to covid contagion reached 41. As for the other professionals, in this group we find economists, engineers, unemployed, self-employed, civil servants, laboratory technicians, with $\mathrm{N}=340$.

In Table 2, 93\% of the people who evaluated the course were women. Table 3 shows us the variety of professionals interested in the Mindfulness course, 53\% were from the nursing / TCAE area, the percentage from Hospital-others refers to $20 \%$. The hospital workers that did not identify role group totaled $14 \%$. Finally, health professionals such as Doctors represent $13 \%$.

According to Graph 1, 85\% of the professionals who enrolled in the course were active in the care of their functions, $11 \%$ were on sick leave, $3 \%$ reported that they were
Others (teleworking, vacations, maternity leave, $2 \%$, home isolation and another $1 \%$, unemployment situation. Registered professionals are in a range of 27 to 63 years.

In state final of Mindfulness course, professionals were asked to complete a survey based on (CSQ-8: Client Satisfaction Questionnaire) [26] voluntarily and anonymously, whose Cronbach's alpha $=0.917$ is why the instrument used with $\mathrm{N}=130$ participants has high reliability and the general characteristics of the professionals are presented in Table 4.

In Table 4 , the $93 \%$ of the women answered this survey, of which $62 \%$ are professionals in the nursing area and the rest of the professionals who took advantage of the course were doctors $12 \%$, others related to health with $26 \%$.

According to Table 4, some workplace of healthcare professionals in the Critical Care Unit (UVI / REA) with 8\%, Primary Care with 10\%, 35\% belonging to other professionals within the Hospital and $21 \%$ to administration professionals, related technicians with the health sector.

We also observe that by age ranges, $42 \%$ of the participating professionals are between 36 and 45 years old and $29 \%$ are between $46-$ and 55 -years old professionals with experience by Table 4 .

Overall, the health professionals who responded to the mindfulness course satisfaction survey indicated the following in Table 5 (CSQ-8 items detail in the appendix Table 8).

According to Table 5, shows question C1, 62\% of the health professionals evaluated the course as highly satisfied and Satisfied with 35\%. In relation to C2, Professionals indicated $47 \%$ highly satisfied and Satisfied with $49 \%$ on the class of service required, they fulfilled what was required.

In relation to $\mathrm{C} 2$, Professionals indicated $47 \%$ highly satisfied and Satisfied with $49 \%$ on the class of service required, they fulfilled what was required. In C3, where they asked whether the course had helped them solve their problems
Graph 1 Current Work Situation

\section{Current Work Situation (in relation to Covid-19)}

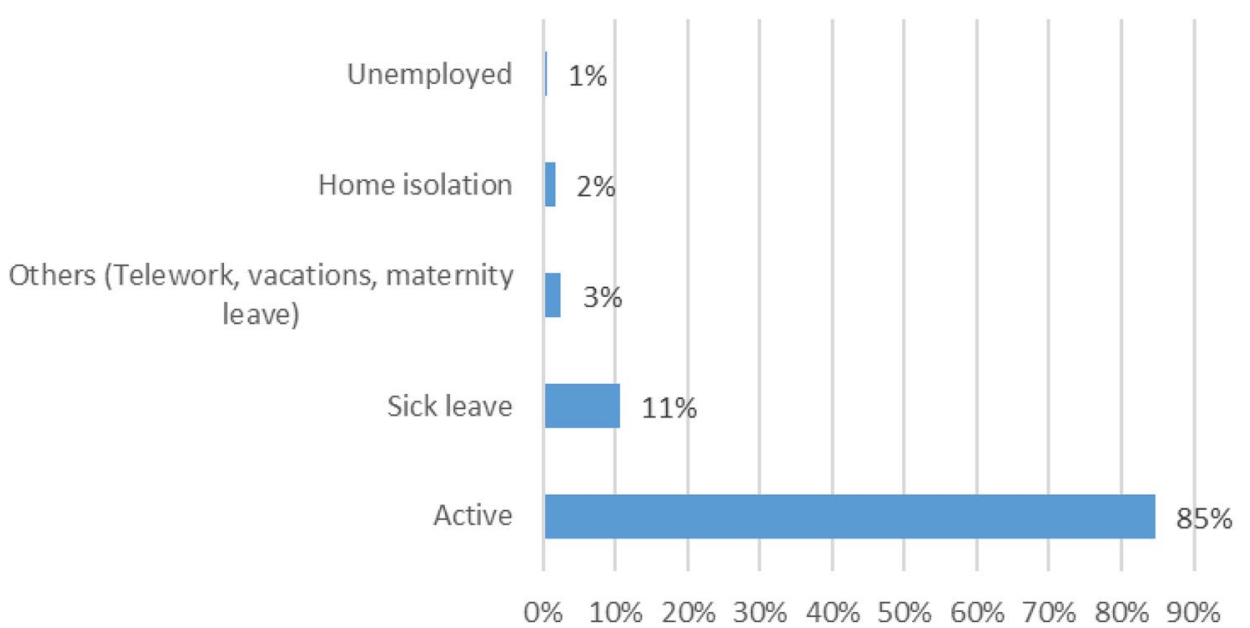


(emotional distress), 21\% highly satisfied and Satisfied with $46 \%$ who indicated that for the most part this course has helped them solve their problems. In this question, $33 \%$ indicated dissatisfied.

In $\mathrm{C} 4,65 \%$ indicated that they would recommend the program if a friend was in the same need for help and 33\% indicated that they would recommend it for a level of satisfied.

With regard C6, the services received helped him face his problems was evaluated with $58 \%$ high satisfaction and $36 \%$ satisfaction, making a total of $94 \%$ of professionals who helped them mindfulness by Table 5 .

In $\mathrm{C} 7$, the professionals indicated a high percentage of satisfaction with the course, with $70 \%$ of the service received, which validates what was answered in $\mathrm{C} 2$. As answered in $\mathrm{C} 8,66 \%$ answered with a highly satisfied that they would return to the mindfulness program, which corresponds to what was answered in $\mathrm{C} 4$ and $\mathrm{C} 1$ by Table 5 .

According to Table 6, we can observe important aspects about the mindfulness course applied to health professionals during the first Wave of Covid-19. When asked if the duration of the intervention was short, the professionals responded with $10 \%$ in complete agreement, $39 \%$ in agreement and $21 \%$ were not sure, $25 \%$ in disagreement, which indicates that only $5 \%$ considered that the duration was short, the rest were not.

The degree of privacy and respect for privacy was considered with $65 \%$ and $30 \%$ completely and in agreement respectively, as an action that was considered and complied with. The sessions were carried out with Zoom at the scheduled times, and with access by password.

In relation to the online system used in the Mindfulness intervention, 74\% expressed that they fully agreed that it was easy to use the online system for the mindfulness intervention by Table 6 .

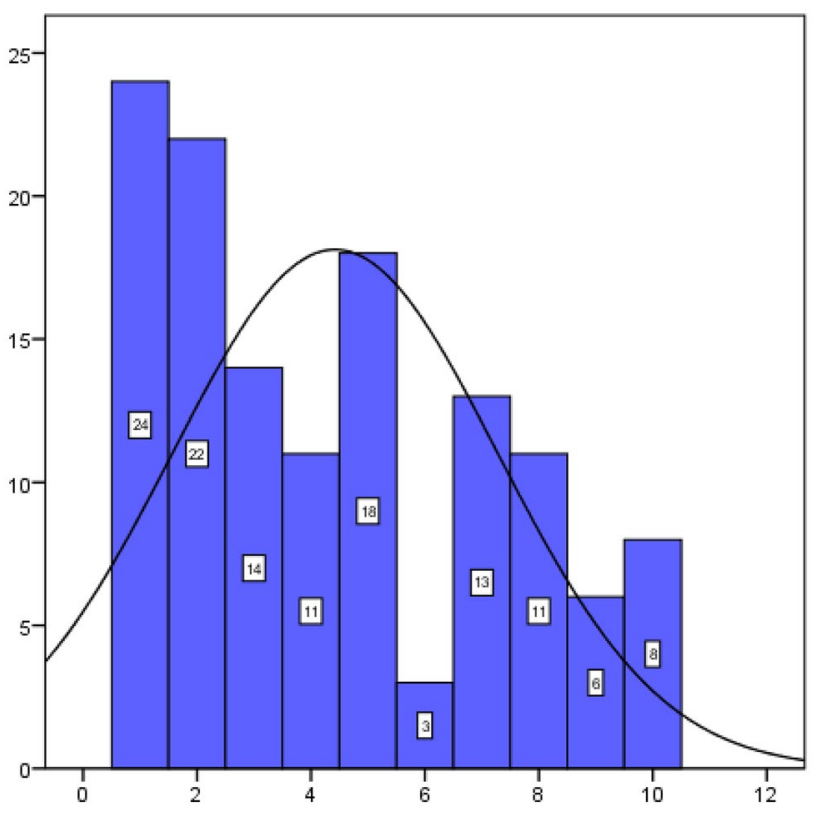

Graph 2 Mindfulness course intervention preferences ( $1=$ Online, 5 indifferent, 10 Face-to-face)

According to Graph 2, where we compare the face-to-face (face-to-face) and online intervention by means of a linear scale, we can see that the majority select the online option when approaching the values 1 and 2, over the face-to-face one.

By making associations between the Mindfulness course preference intervention with the following variables, we obtain the following:

- When verifying if there is a difference between the age group of the participating professionals, the $\mathrm{H}$. Kruskal -Wallis statistical test is carried out, obtaining
Graph 3 Difference of means by age groups

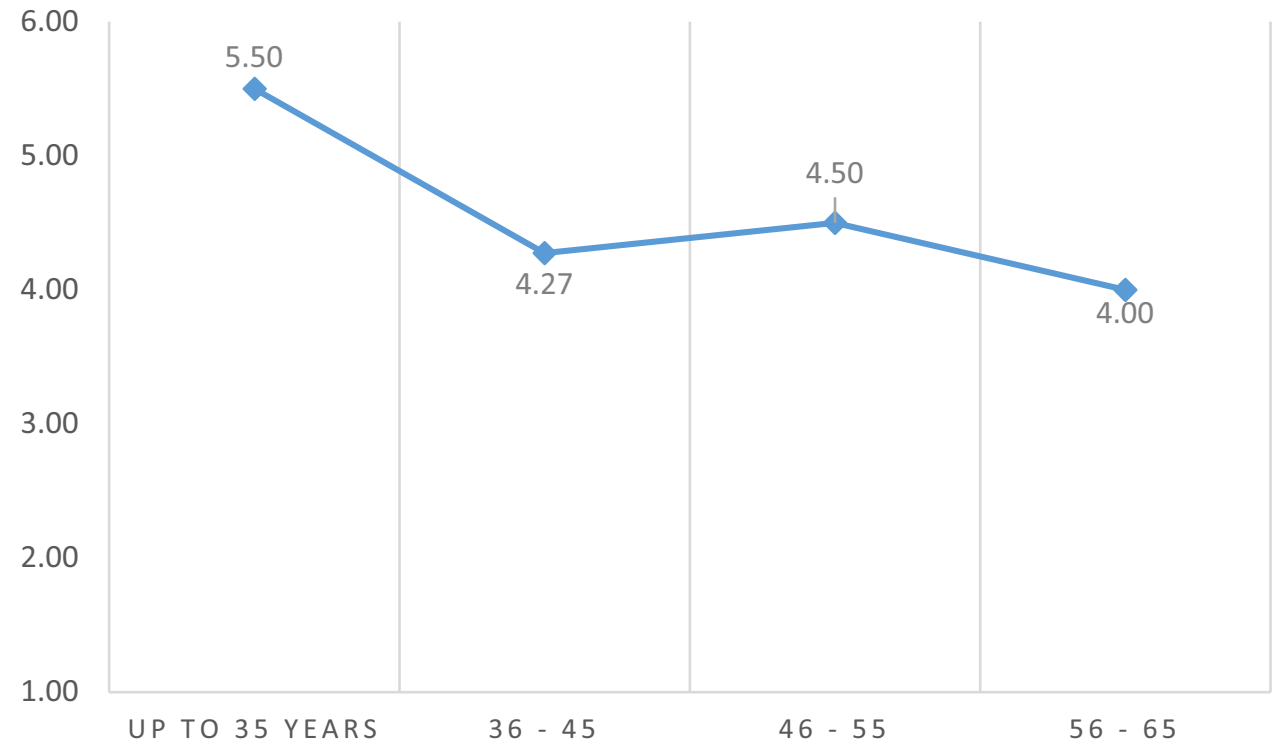


Table 1 Distribution of the frequencies of the variables considered in the Reason and demand of the Course

\begin{tabular}{|c|c|c|c|c|c|c|}
\hline Reason for the claim & \multicolumn{5}{|c|}{ Reason for Concern-First Wave Covid-19 } & \\
\hline $\begin{array}{c}\text { First Wave-Covid19 of the } \\
\text { MindFulness course }\end{array}$ & $\begin{array}{l}\text { work } \\
\text { stress }\end{array}$ & $\begin{array}{l}\text { Stress for } \\
\text { relatives (not sick } \\
\text { with covid-19) }\end{array}$ & $\begin{array}{l}\text { Stress for } \\
\text { relatives (patients } \\
\text { with covid-19) }\end{array}$ & $\begin{array}{l}\text { Stress due } \\
\text { to covid-19 } \\
\text { contagion }\end{array}$ & Others & Total \\
\hline Anxiety & 93 & 14 & 5 & 7 & \begin{tabular}{|l|}
5 \\
\end{tabular} & 124 \\
\hline Insomnia & 23 & 6 & 0 & 7 & 2 & 38 \\
\hline Depressed mood & 7 & 2 & 0 & 2 & 1 & 12 \\
\hline Psycho-emotional support & 80 & 19 & 4 & 25 & 12 & 140 \\
\hline Others & 10 & 5 & 1 & 0 & 10 & 26 \\
\hline Total & 213 & 46 & 10 & 41 & 30 & 340 \\
\hline
\end{tabular}

$p=0.672>0.05$, we can conclude that there is no difference between the age group with $95 \%$ confidence. We can also observe Graph 3.

- To check if there is a difference between the group of type of professionals, the H. Kruskal -Wallis statistical test is carried out, obtaining $p=0.001<0.05$, we can conclude that there is a difference between types of professionals.

- We associate with workplace of participating professionals, the H. Kruskal -Wallis statistical test is carried out, obtaining $\mathrm{p}=0.01<0.05$, we can conclude that there is a difference between workplace of professionals with $95 \%$ confidence.

\section{Discussion}

The uncertainty and work overload during the pandemic in the first wave of Covid-19, led health professionals in many cases to be affected by emotional distress.

Given the high demand for Support, the need to maintain privacy and the stress that the hospital generated in itself, as well as the extension of hours in the hospital, led the Research team to carry out an intervention program based on mindfulness intervention that could meet the requirements and demands collected:
- Easy accessibility.

- Preserve privacy.

- Intervene for emotional improvement without prejudging any previous mental pathology or during the intervention.

Due to the experience in the mindfulness intervention of one of the authors (OS-M), this type of intervention was proposed, which had shown its efficacy in various settings [29-31], although it was difficult to apply it in people, who were sometimes doing 12-h shifts, motivated us to offer the course in an online application format, through the use of new technologies and supported by some studies that showed great possibilities for this type of application [32, 33].

The first issue to highlight is the high number of participants, 359, which is an unthinkable number to reach so quickly with a traditional application, which would also be significantly more expensive. Considering that the diffusion had been limited and that it was being a pilot project, this high number was not surprising. In fact, we have not found studies of this type with such a large number of participants.

Also although the study design of being online was optimal during a pandemic wave, this may or may not be comparable to traditional models of supportive care [34].

The greatest demand for the course is among women and nursing workers, which could lead to the assumption
Table 2 Frequency distribution-by Sex (initial state and final time) of the Mindfulness course participants

Table 3 Distribution of the frequencies of the types of health professionals

\begin{tabular}{|l|r|r|r|r|}
\hline \multicolumn{3}{|c|}{ Initial State of the Course } & \multicolumn{2}{c|}{ Final Status of the Course } \\
\hline Gender & Frequency & $\%$ & Frequency & $\%$ \\
\hline Woman & 340 & $95 \%$ & 121 & $93 \%$ \\
\hline Man & 19 & $5 \%$ & 9 & $7 \%$ \\
\hline Total & 359 & $100 \%$ & 130 & $100 \%$ \\
\hline
\end{tabular}

\begin{tabular}{|c|c|c|}
\hline Types of Professionals & Frequency & $\%$ \\
\hline Nurse / TCAE * & 189 & $53 \%$ \\
\hline Hospital-Others & 73 & $20 \%$ \\
\hline Others & 52 & $14 \%$ \\
\hline Doctors & 45 & $13 \%$ \\
\hline
\end{tabular}

*Nursing Auxiliary Care Technician (TCAE) 
Table 4 General characteristics of the professionals

\begin{tabular}{|c|c|c|}
\hline Features & Frequency & $\%$ \\
\hline \multirow{2}{*}{ Gender } & Woman $=121$ & $93 \%$ \\
\hline & Man $=9$ & $7 \%$ \\
\hline \multirow{4}{*}{ Age } & up to 35 years $=14$ & $11 \%$ \\
\hline & $36-45$ years $=55$ & $42 \%$ \\
\hline & $46-55$ years $=38$ & $29 \%$ \\
\hline & $56-65$ years $=23$ & $18 \%$ \\
\hline \multirow{3}{*}{ type of professional } & Nursing/TCAE $=81$ & $62 \%$ \\
\hline & Others $=34$ & $26 \%$ \\
\hline & Doctors $=15$ & $12 \%$ \\
\hline \multirow{7}{*}{ Workplace } & Hospital - Others $=45$ & $35 \%$ \\
\hline & Others $=27$ & $21 \%$ \\
\hline & Emergency-Hospital $=21$ & $16 \%$ \\
\hline & Primary care $=13$ & $10 \%$ \\
\hline & Critical Care Unit (UVI/REA) $=11$ & $8 \%$ \\
\hline & Internal Medicine / Pulmonology $=8$ & $6 \%$ \\
\hline & Mental health $=5$ & $4 \%$ \\
\hline
\end{tabular}

that this type of intervention should be fitted mainly to women and nurses for being the main attenders, which should also be considered as a measure tending to provide a preferential service to women, about $93 \%$ are preferred by women. According to Graph $1,85 \%$ of the professionals who enrolled in the course were active in the care of their functions and $11 \%$ were on sick leave, what means that this kind of approach can be useful for preventing to get sick but can be a good support for people already sick demanding a psychological support. Considering the figures and acceptation/satisfaction of the therapy it should be considered as probably the best tool for facing to the emotional problems in the health works linked to the outbreak.

The challenge then was based on achieving satisfaction for the attendees both in relation to the program and its means of application. In general, psychologist and therapist are reluctant to the online interventions [35] and so, it was important to know the level of acceptation and usability of this online approach [36]. Then it is observed that in general the degree of acceptance by the attenders is very high, with a very good interactive response and that there is even a general preference for its application online over the face-to-face route. This is influenced by privacy, comfort and avoidance of spending more time in the hospital where they may have had 12-h shifts. So, despite of the barriers of implementing this kind of therapies, it's good to try them more because users welcome them with high satisfaction [37].

In general, $62 \%$ of health professionals evaluated the course as excellent and Good with $35 \%$, which in total allows us to say that $98 \%$ indicate that there is great satisfaction about the application of this type of therapy by $\mathrm{C} 1$, with many cases in which the acceptance of it improved compared to traditional treatments, which leads to consider that online intervention should be considered in cases, such as the present, in which the demand is great, the resources are scarce and social distance is maintained. Indeed, traditional videoconferencing system has proved sufficient capacity to be able to connect with health professionals, as well as the possibility of greater participation since it can be followed from any point, rising the accessibility.
Table 5 Frequency distribution of client satisfaction questionnaire by each question in Castilla y Leon, 2020 $(\mathrm{n}=130)$

\begin{tabular}{|l|r|l|r|l|r|r|}
\hline CSQ-8: items & Highly Satisfied & $\%$ & Satisfied & $\%$ & Dissatisfied & $\%$ \\
\cline { 2 - 8 } C1 & 81 & $62 \%$ & 46 & $35 \%$ & 3 & $2 \%$ \\
\cline { 2 - 8 } C2 & 61 & $47 \%$ & 64 & $49 \%$ & 5 & $4 \%$ \\
\cline { 2 - 8 } C3 & 27 & $21 \%$ & 60 & $46 \%$ & 43 & $33 \%$ \\
\hline C4 & 85 & $65 \%$ & 43 & $33 \%$ & 2 & $2 \%$ \\
\hline C5 & 85 & $65 \%$ & 38 & $29 \%$ & 7 & $5 \%$ \\
\hline C6 & 76 & $58 \%$ & 47 & $36 \%$ & 7 & $5 \%$ \\
\cline { 2 - 7 } C8 & 91 & $70 \%$ & 28 & $22 \%$ & 11 & $8 \%$ \\
\hline
\end{tabular}


Table 6 C9. Evaluation of General aspects in terms of Quantity and Percentages of the Mindfulness Course

\begin{tabular}{|c|c|c|c|c|c|c|c|c|c|c|}
\hline C9. & Comp & gree & & & & & In dis & tent & Strongly Dis & gree \\
\hline $\begin{array}{l}\text { The duration of the intervention you } \\
\text { consider could be too short }\end{array}$ & 13 & $10 \%$ & 50 & $39 \%$ & 27 & $21 \%$ & 33 & $25 \%$ & 7 & $5 \%$ \\
\hline $\begin{array}{l}\text { The degree of privacy and respect for } \\
\text { privacy has been considered and met. }\end{array}$ & 84 & $65 \%$ & 39 & $30 \%$ & 5 & $4 \%$ & 1 & $1 \%$ & 1 & $1 \%$ \\
\hline I have felt comfortable during therapy & 88 & $68 \%$ & 35 & $27 \%$ & 4 & $3 \%$ & 1 & $1 \%$ & 2 & $2 \%$ \\
\hline $\begin{array}{l}\text { You consider the duration of the } \\
\text { intervention to be too short }\end{array}$ & 13 & $10 \%$ & 57 & $44 \%$ & 24 & $19 \%$ & 29 & $22 \%$ & 7 & $5 \%$ \\
\hline $\begin{array}{l}\text { The online system has been easy to } \\
\text { use }\end{array}$ & 96 & $74 \%$ & 28 & $22 \%$ & 4 & $3 \%$ & 1 & $1 \%$ & 1 & $1 \%$ \\
\hline $\begin{array}{l}\text { Due to his experience as a health } \\
\text { professional, he considers that the } \\
\text { program would be convenient and offer a } \\
\text { similar program for those affected by } \\
\text { covid- } 19 \text { and / or their families }\end{array}$ & 103 & $79 \%$ & 22 & $17 \%$ & 4 & $3 \%$ & 0 & $0 \%$ & 1 & $1 \%$ \\
\hline $\begin{array}{l}\text { Based on his experience with the } \\
\text { pandemic, and if there were another } \\
\text { similar situation, he considers that a } \\
\text { program like this one should be } \\
\text { promoted. }\end{array}$ & 112 & $86 \%$ & 14 & $11 \%$ & 2 & $2 \%$ & 1 & $1 \%$ & 1 & $1 \%$ \\
\hline
\end{tabular}

\section{Conclusions}

Participants were asked to complete a survey based on (CSQ-8: Client Satisfaction Questionnaire) [25] voluntarily and anonymously, whose Cronbach's alpha $=0.917$ is why the instrument used with $\mathrm{N}=130$ participants has high reliability.

The $93 \%$ of the people who answered the satisfaction survey were women, of which they are professionals in the nursing area, with a participation of around $62 \%$.

The $62 \%$ of the health professionals evaluated the course like highly satisfied and Satisfied with $35 \%$ by question $\mathrm{C} 1$. The $65 \%$ indicated that they would recommend the program if a friend was in the same need for help and 33\% indicated that they would recommend it for a level of satisfied.

Health Professionals responded with $58 \%$ high satisfaction and $36 \%$ satisfaction, making a total of $94 \%$ on the help received in the online mindfulness courses to solve their problems.

The degree of privacy and respect for privacy was considered with $65 \%$ and $30 \%$ completely and in agreement respectively, as an action that was considered and complied with.

In relation to the online system used in the Mindfulness intervention, $74 \%$ expressed that they fully agreed that it has been easy to use the online system for the mindfulness intervention.

According to the Kruskal-Wallis test, there is no difference between the age groups of the professionals who have preferred the Mindfulness online course $(p=0.672)$.

Finally, this online mindfulness experience was organized spontaneously by professionals who had the initiative to innovate in times of COVID-19 and to provide mental support to professionals to prevent risks associated with their workload. Although this approach was used due to the pandemic as a way to offer supportive services, the implications for practice as we move from the pandemic may meet healthcare workers needs of support in a convenient way through online programs.

Future work will continue to provide more mindfulness courses to support health personnel in the COVID-19 pandemic.

Acknowledgements This project has been supported by Gerencia Regional de Salud (Castilla y Leon Health Service) through a grant GRS COVID 90/A/20.

\section{Declarations}

Conflict of Interest The authors declare that they have no conflict of interest.

Ethical Approval Approved ethical committee code: PI149-20 by CEim ("Comité de Ética de la Investigación con Medicamentos área de salud valladolid"/ committee of ethics for research with medicines Valladolid health area) Spain.

Open Access This article is licensed under a Creative Commons Attribution 4.0 International License, which permits use, sharing, adaptation, distribution and reproduction in any medium or format, as long as you give appropriate credit to the original author(s) and the source, provide a link to the Creative Commons licence, and indicate if changes were made. The images or other third party material in this article are included in the article's Creative Commons licence, unless indicated otherwise in a credit line to the material. If material is not included in the article's Creative Commons licence and your intended use is not permitted by statutory regulation or exceeds the permitted use, you will need to obtain permission directly from the copyright holder. To view a copy of this licence, visit http://creativecommons.org/licenses/by/4.0/. 


\section{Appendix}

Table 7 Registration to the Mindfulness Course in time of the COVID-9 Pandemic

\begin{tabular}{|c|c|c|}
\hline ID & Question & Answers \\
\hline \multirow[t]{5}{*}{ Item 0} & E-mail & Email \\
\hline & Name and surname & Text \\
\hline & Age & Numerical quantity \\
\hline & Sex & $\begin{array}{l}\text { woman } \\
\text { man }\end{array}$ \\
\hline & Workplace & $\begin{array}{l}\text { Nurse / TCAE } \\
\text { Doctor } \\
\text { Hospital-other } \\
\text { Hospital-emergencies }\end{array}$ \\
\hline 1 & $\begin{array}{l}\text { Knowledge of the program } \\
\text { and type of referral: }\end{array}$ & $\begin{array}{l}\text { By e-mail } \\
\text { By Direct Contact } \\
\text { By phone } \\
\text { By the traditional system (Interconsultation) } \\
\text { Social media }\end{array}$ \\
\hline 2 & $\begin{array}{l}\text { Current work situation (in } \\
\text { relation to COVID-19): }\end{array}$ & $\begin{array}{l}\text { Active } \\
\text { Sick leave } \\
\text { Home isolation } \\
\text { Unemployed } \\
\text { Others: telecommuting, maternity leave, freelance, vacations }\end{array}$ \\
\hline 3 & Reason for the demand & $\begin{array}{l}\text { Anxiety } \\
\text { Insomnia } \\
\text { Depressed mood } \\
\text { Psycho-emotional support } \\
\text { Others }\end{array}$ \\
\hline 4 & $\begin{array}{l}\text { Main reason for concern } \\
\text { associated with Covid-19 }\end{array}$ & $\begin{array}{l}\text { Work stress } \\
\text { Stress for relatives (not sick with covid-19) } \\
\text { Stress for relatives (patients with covid-19) } \\
\text { Stress due to covid-19 contagion } \\
\text { others (Concern about the social consequences (unemploy- } \\
\text { ment, economy) of the pandemic, emotional control, uncer- } \\
\text { tainty, proximity of vulnerable people, relatives, deceased by } \\
\text { covid) Hostility between colleagues in the service ... }\end{array}$ \\
\hline
\end{tabular}


Table 8 Survey based on Client Satisfaction Questionnaire (CSQ-8)

\begin{tabular}{ll}
\hline ID & Question \\
\hline Item 0 & $\begin{array}{l}\text { Type of professional } \\
\text { Age } \\
\text { Gender }\end{array}$ \\
& $\begin{array}{l}\text { Workplace } \\
\text { Item } 1 \quad \text { How would you evaluate the quality of the mindfulness online emotional support service } \\
\text { you have received? }\end{array}$
\end{tabular}

Item 2 2. Did you receive the kind of service you required?

Item 3 3. What extent has this program helped you to solve your problems?

Answers

text

Numerical quantity

Woman

Man

text

Excellent

Good

Regular

$\mathrm{Bad}$

No, definitely

In very few

Yes, in general

Yes, definitely

In almost all

For the most part

Only in some

None

Item 4 4. If a friend were in need of similar help, I would recommend this program

Item 5 5. How satisfied are you with the amount of help you have received?

Item 6 6. Have the services you received helped you cope better with your problems?

Item 7 7. Overall, how satisfied are you with the services you have received?

Item 8 8. If you needed help again, would you return to our program?

Item 9 9. About the Course:

- [Do you think the duration of the intervention could have been too short]

- [The degree of privacy and respect for privacy has been considered and complied with]

- [I have felt comfortable during therapy]

- [Do you think the duration of the intervention could have been too short]

- [The online system has been easy to use]

- [Due to his experience as a healthcare professional, he considers that the program would be convenient and offer a similar program for those affected by covid-19 and / or their families]

- [Due to his experience with the pandemic, and if there were another similar situation, he considers that a program like this should be promoted.]

Item 10 10. Comparing the in-person (face-to-face) and online intervention, if you had to choose and after the lived experience, where would you place your preferences (A five [5] would be that you are indifferent for both types of interventions):

Item 11 Optional:

-Share with us what you liked the most about the attention received

-Share with us your suggestions and recommendations to improve
No, definitely

No, I think No

Yes, I think so

Yes, definitely

Not satisfied at all

Indifferent or moderately dissatisfied

Moderately satisfied

Very satisfied

Yes, they helped me a lot

Yes, they helped me something

No, they really didn't help me

No, they seemed to make things worse

Very satisfied

Moderately satisfied

Somewhat Satisfied

Very dissatisfied

No, definitely

No possibly

Yes, I think so

Yes, for sure

Completely agree

In agreement

I'm not sure

In disagreement

Strongly disagree

Scale [1 Online-10 face-to-face]

Open Answers 


\section{References}

1. L. Kang et al., "The mental health of medical workers in Wuhan, China dealing with the 2019 novel coronavirus," The Lancet Psychiatry, vol. 7, no. 3. Elsevier Ltd, p. e14, Mar. 01, 2020, https:// doi.org/10.1016/S2215-0366(20)30047-X.

2. Y. T. Xiang et al., "Timely mental health care for the 2019 novel coronavirus outbreak is urgently needed," The Lancet Psychiatry, vol. 7, no. 3. Elsevier Ltd, pp. 228-229, Mar. 01, 2020, https://doi. org/10.1016/S2215-0366(20)30046-8.

3. . Wu et al., "The psychological impact of the SARS epidemic on hospital employees in China: Exposure, risk perception, and altruistic acceptance of risk," Can. J. Psychiatry, vol. 54, no. 5, pp. 302-311, May 2009, https://doi.org/10.1177/070674370905400504

4. Y. T. Xiang et al., "Timely research papers about COVID-19 in China," The Lancet, vol. 395, no. 10225. Lancet Publishing Group, pp. 684-685, Feb. 29, 2020, https://doi.org/10.1016/ S0140-6736(20)30375-5.

5. C. Xiao, "A novel approach of consultation on 2019 novel coronavirus (COVID-19)-related psychological and mental problems: Structured letter therapy," Psychiatry Investigation, vol. 17, no. 2. Korean Neuropsychiatric Association, pp. 175-176, Feb. 01, 2020, https://doi.org/10.30773/pi.2020.0047.

6. S. Cohen, W. J. Doyle, and D. P. Skoner, "Psychological stress, cytokine production, and severity of upper respiratory illness," Psychosom. Med., vol. 61, no. 2, pp. 175-180, 1999, https://doi. org/10.1097/00006842-199903000-00009.

7. F. Dutheil et al., "Suicide among physicians and health-care workers: A systematic review and meta-analysis," PLoS One, vol. 14, no. 12, p. e0226361, Dec. 2019, https://doi.org/10.1371/journal.pone. 0226361.

8. M. A. Reger, I. H. Stanley, and T. E. Joiner, "Suicide Mortality and Coronavirus Disease 2019-A Perfect Storm?," JAMA Psychiatry, vol. 77 , no. 11, p. 1093, 2020, https://doi.org/10.1001/ jamapsychiatry.2020.1060.

9. E. Shonin, W. Van Gordon, and M. D. Griffiths, "Mindfulnessbased interventions: towards mindful clinical integration," Front. Psychol., vol. 4, no. APR, 2013, https://doi.org/10.3389/fpsyg. 2013.00194

10. M. Sharma, S. Sharma, and G. Singh, "Remote monitoring of physical and mental state of 2019-nCoV victims using social internet of things, fog and soft computing techniques," Comput. Methods Programs Biomed., vol. 196, Nov. 2020, https://doi.org/ 10.1016/J.CMPB.2020.105609.

11. M. Sharma, "Drone Technology for Assisting COVID-19 Victims in Remote Areas: Opportunity and Challenges," J. Med. Syst. 2021 459, vol. 45, no. 9, pp. 1-2, Jul. 2021, https://doi.org/10. 1007/S10916-021-01759-Y.

12. M. Sharma, "m-health services for COVID-19 afflicted and infected victims," EAI Endorsed Trans. Pervasive Heal. Technol., p. 170232, 2021, https://doi.org/10.4108/eai.11-6-2021.170232.

13. S. de Sio et al., "Consequences of COVID19-pandemic lockdown on Italian occupational physicians' psychosocial health," PLoS One, vol. 16, no. 2, Feb. 2021, https://doi.org/10.1371/JOURNAL. PONE.0243194.

14. P. Kaur and M. Sharma, "Diagnosis of Human Psychological Disorders using Supervised Learning and Nature-Inspired Computing Techniques: A Meta-Analysis," J. Med. Syst. 2019 437, vol. 43, no. 7, pp. 1-30, May 2019, https://doi.org/10.1007/ S10916-019-1341-2.

15. P. Kaur, R. Gautam, and M. Sharma, "Feature Selection for Biobjective Stress Classification Using Emerging Swarm Intelligence Metaheuristic Techniques," Lect. Notes Data Eng. Commun. Technol., vol. 91, pp. 357-365, 2022, https://doi.org/10. 1007/978-981-16-6285-0_29.
16. S. Sharma, G. Singh, and M. Sharma, "A comprehensive review and analysis of supervised-learning and soft computing techniques for stress diagnosis in humans," Comput. Biol. Med., vol. 134, p. 104450, Jul. 2021, https://doi.org/10.1016/J.COMPBIOMED. 2021.104450

17. S. Sharma, M. Sharma, and G. Singh, "A chaotic and stressed environment for 2019-nCoV suspected, infected and other people in India: Fear of mass destruction and causality," Asian J. Psychiatr., vol. 51, p. 102049, Jun. 2020, Accessed: May 27, 2021. [Online]. Available: /pmc/articles/PMC7146677/.

18. R. A. Baer, "Mindfulness Training as a Clinical Intervention: A Conceptual and Empirical Review," Clin. Psychol. Sci. Pract., vol. 10, no. 2, pp. 125-143, May 2003, https://doi.org/10.1093/clipsy/ bpg015.

19. S. G. Hofmann and A. F. Gómez, "Mindfulness-Based Interventions for Anxiety and Depression," https://doi.org/10.1016/j.psc. 2017.08.008.

20. C. Crane, T. Barnhofer, D. S. Duggan, S. Hepburn, M. V. Fennell, and J. M. G. Williams, "Mindfulness-based cognitive therapy and self-discrepancy in recovered depressed patients with a history of depression and suicidality," Cognit. Ther. Res., vol. 32, no. 6, pp. 775-787, Dec. 2008, https://doi.org/10.1007/s10608-008-9193-y.

21. V. K. Arlt Mutch, S. Evans, and K. Wyka, "The role of acceptance in mood improvement during Mindfulness-Based Stress Reduction," J. Clin. Psychol., Jan. 2020, https://doi.org/10.1002/jclp. 23017.

22. M. A. Franco-Martín, J. L. Muñoz-Sánchez, B. Sainz-de-Abajo, G. Castillo-Sánchez, S. Hamrioui, and I. de la Torre-Díez, "A Systematic Literature Review of Technologies for Suicidal Behavior Prevention," J. Med. Syst., 2018, https://doi.org/10.1007/ s10916-018-0926-5.

23. K. Okoye, J. T. Nganji, and S. Hosseini, "Learning analytics: The role of information technology for educational process innovation," in Advances in Intelligent Systems and Computing, 2021, vol. 1180 AISC, pp. 272-284, https://doi.org/10.1007/978-3-03049339-4_28.

24. Zoom, "Videoconferencias, conferencias web, seminario web, uso compartido de pantalla - Zoom." https://zoom.us/ (accessed Nov. 22, 2020).

25. Sacyl, “+Salud Mental,” Home, 2020. https://www.massaludmental. es/ (accessed Jun. 10, 2021)

26. C. C. Attkisson and R. Zwick, "THE CLIENT SATISFACTION QUESTIONNAIRE Psychometric Properties and Correlations with Service Utilization and Psychotherapy Outcome," 1982.

27. M. H. Bornstein, J. Jager, and D. L. Putnick, "Sampling in developmental science: Situations, shortcomings, solutions, and standards," Developmental Review, vol. 33, no. 4. Academic Press, pp. 357-370, Dec. 01, 2013, https://doi.org/10.1016/j.dr.2013.08.003.

28. M. J. Acosta et al., "Sentiment Analysis Techniques Applied to Raw-Text Data from a Csq-8 Questionnaire about Mindfulness in Times of COVID-19 to Improve Strategy Generation," Public Health, vol. 18, no. 12, p. 6408, Jun. 2021, https://doi.org/10.3390/ ijerph18126408.

29. M. Cavicchioli, M. Movalli, and C. Maffei, "The Clinical Efficacy of Mindfulness-Based Treatments for Alcohol and Drugs Use Disorders: A Meta-Analytic Review of Randomized and Nonrandomized Controlled Trials," European Addiction Research, vol. 24, no. 3. S. Karger AG, pp. 137-162, Jul. 01, 2018, https://doi.org/10. $1159 / 000490762$

30. J. H. Hearn and A. Cross, "Mindfulness for pain, depression, anxiety, and quality of life in people with spinal cord injury: A systematic review," BMC Neurol., vol. 20, no. 1, p. 32, Jan. 2020, https://doi.org/10.1186/s12883-020-1619-5.

31. K. L. Rieger et al., "Mindfulness-based arts interventions for cancer care: A systematic review of the effects on wellbeing and 
fatigue," Psychooncology., p. pon.5560, Oct. 2020, https://doi.org/ 10.1002/pon.5560.

32. L. N. Lyzwinski, L. Caffery, M. Bambling, and S. Edirippulige, "A Systematic Review of Electronic Mindfulness-Based Therapeutic Interventions for Weight, Weight-Related Behaviors, and Psychological Stress," Telemedicine and e-Health, vol. 24, no. 3. Mary Ann Liebert Inc., pp. 173-184, Mar. 01, 2018, https://doi. org/10.1089/tmj.2017.0117.

33. M. P. J. Spijkerman, W. T. M. Pots, and E. T. Bohlmeijer, "Effectiveness of online mindfulness-based interventions in improving mental health: A review and meta-analysis of randomised controlled trials," Clinical Psychology Review, vol. 45. Elsevier Inc., pp. 102-114, Apr. 01, 2016, https://doi.org/10.1016/j.cpr.2016. 03.009.

34. N. Geurtzen, G. P. J. Keijsers, J. C. Karremans, and G. J. M. Hutschemaekers, "Patients' care dependency in mental health care: Development of a self-report questionnaire and preliminary correlates," J. Clin. Psychol., vol. 74, no. 7, pp. 1189-1206, Jul. 2018, https://doi.org/10.1002/jclp.22574.
35. A. Interian, A. R. King, L. M. St. Hill, C. H. Robinson, and L. J. Damschroder, "Evaluating the implementation of home-based videoconferencing for providing mental health services," Psychiatr. Serv., vol. 69, no. 1, pp. 69-75, Jan. 2018, https://doi.org/10. 1176/appi.ps.201700004.

36. S. D. Muir, K. de Boer, M. Nedeljkovic, and D. Meyer, "Barriers and facilitators of videoconferencing psychotherapy implementation in veteran mental health care environments: a systematic review," BMC Health Serv. Res., vol. 20, no. 1, p. 999, Dec. 2020, https://doi.org/10.1186/s12913-020-05858-3.

37. G. Andersson and N. Titov, "Advantages and limitations of Internet-based interventions for common mental disorders," World Psychiatry, vol. 13, no. 1, pp. 4-11, Feb. 2014, https://doi.org/10. 1002/wps.20083.

Publisher's Note Springer Nature remains neutral with regard to jurisdictional claims in published maps and institutional affiliations. 